\title{
Sleep apnoea and metabolic dysfunction
}

\author{
Maria R. Bonsignore ${ }^{1,2}$, Anne-Laure Borel ${ }^{3,4,5}$, Elizabeth Machan ${ }^{6}$ and \\ Ron Grunstein ${ }^{6}$
}

\begin{abstract}
Affiliations: 'Biomedical Dept of Internal and Specialistic Medicine (DiBiMIS), Section of Pneumology, University of Palermo, Palermo, and ${ }^{2}$ Institute of Biomedicine and Molecular Immunology (IBIM), National Research Council (CNR), Palermo, Italy. ${ }^{3}$ Endocrinology Dept, University Hospital, Grenoble, ${ }^{4}$ INSERM U1042, Grenoble, and ${ }^{5}$ University Grenoble Alpes, HP2, Grenoble, France. ${ }^{6}$ Centre for Integrated Understanding and Research into Sleep (CIRUS), Woolcock Institute, University of Sydney and Royal Prince Alfred Hospital, Glebe,
\end{abstract} Australia.

Correspondence: M.R. Bonsignore, Biomedical Dept of Internal and Specialistic Medicine (DiBiMIS), Section of Pneumology, University of Palermo, Via Trabucco 180, Palermo 90146, Italy. E-mail: marisa@ibim.cnr.it

ABSTRACT Obstructive sleep apnoea (OSA) is a highly prevalent condition often associated with central obesity. In the past few years, several studies have analysed the potential independent contribution of OSA to the pathogenesis of metabolic abnormalities, including type 2 diabetes, the metabolic syndrome and nonalcoholic fatty liver disease. New perspectives in OSA patient care have been opened by the promotion of lifestyle interventions, such as diet and exercise programmes that could improve both OSA and the metabolic profile. The rich clinical literature on this subject, together with the growing amount of data on pathophysiological mechanisms provided by animal studies using the chronic intermittent hypoxia model, urged the organising Committee of the Sleep and Breathing meeting to organise a session on sleep apnoea and metabolic dysfunction, in collaboration with the European Association for the Study of Diabetes. This review summarises the state-of-the-art lectures presented in the session, more specifically the relationship between OSA and diabetes, the role of OSA in the metabolic consequences of obesity, and the effects of lifestyle interventions on nocturnal respiratory disturbances and the metabolic profile in OSA patients.

0 @ERSpublications

Treatment of obesity and metabolic diseases through diet and exercise should be part of OSA management besides CPAP http://ow.ly/mUd1R

\section{Introduction}

Obstructive sleep apnoea (OSA) is a highly prevalent condition often associated with central obesity. In the past few years, the implications of the association of OSA and obesity have raised considerable interest, and several studies have analysed the potential independent contribution of OSA to the pathogenesis of metabolic abnormalities, including type 2 diabetes, the metabolic syndrome and non-alcoholic fatty liver disease. New perspectives in OSA patient care have been opened by the promotion of lifestyle interventions, such as diet and exercise programmes that could improve both OSA and the metabolic profile. The clinical consequence of such approaches will be a better definition of therapeutic and preventive strategies in OSA patients.

The rich clinical literature on this subject, together with the growing amount of data on pathophysiological mechanisms provided by animal studies using the chronic intermittent hypoxia model, urged the organising Committee of the Sleep and Breathing meeting, held in Berlin in April 2013, and jointly organized by European Respiratory Society and the European Sleep Research Society, to organise a session on sleep apnoea and metabolic dysfunction, in collaboration with the European Association for the Study of Diabetes.

Received: May 162013 | Accepted after revision: June 192013

Conflict of interest: None declared.

Provenance: Submitted article, peer reviewed.

Copyright @ERS 2013 
This review summarises the state-of-the-art lectures presented in the session, more specifically the relationship between OSA and diabetes, the role of OSA in the metabolic consequences of obesity, and the effects of lifestyle interventions on nocturnal respiratory disturbances and the metabolic profile in OSA patients.

\section{OSA and type 2 diabetes: an independent relationship?}

OSA and type 2 diabetes are two frequently associated conditions which share the same risk factors, i.e. male sex, advancing age and obesity, particularly abdominal adiposity. The prevalence of type 2 diabetes in OSA patients ranges from $15 \%$ to $30 \%$ depending on the study population, the definition of OSA severity and the methods used to diagnose type 2 diabetes [1]. In the Wisconsin Sleep Study, the prevalence of type 2 diabetes increased according to the severity of OSA, and the odds ratio (OR) of having physician-diagnosed type 2 diabetes was 2.30 (95\% CI 1.28-4.11) when comparing those with an apnoea/hypopnoea index (AHI) of $\geqslant 15$ events $\cdot h^{-1}$ with those with an AHI of $<5$ events $\cdot h^{-1}$. The OR was 3.48 (95\% CI 1.69-7.18) when comparing those with an AHI of $>30$ events $\cdot h^{-1}$ to controls after adjustment for age, sex and waist circumference [2].

Similarly, the prevalence of OSA among patients with type 2 diabetes is high. In the Sleep Heart Health Study [3], the prevalence of OSA (AHI $\geqslant 15$ events $\cdot \mathrm{h}^{-1}$ ) was $24.0 \%$ and $15.6 \%$ in patients with and without type 2 diabetes, respectively. However, the difference in mean AHI between patients with versus without type 2 diabetes was no longer significant after adjustment for age, sex, body mass index (BMI), ethnicity and neck circumference. In the Sleep AHEAD study [4], the prevalence of OSA (AHI $\geqslant 15$ events $\cdot \mathrm{h}^{-1}$ ) was $53 \%$ in overweight or obese patients with type 2 diabetes. Comparing such results to the estimated prevalence of OSA in males and females of the same age range and BMI in the general population [5], the prevalence of OSA among patients with type 2 diabetes [6-8] appears to exceed predictions of OSA in the general population (fig. 1).

Considering the incidence of type 2 diabetes, the presence of OSA has been associated with an increased risk of developing type 2 diabetes in some studies $[8,9]$ but not in others $[2,10]$ after adjustment for confounding factors. Nevertheless, LINDBERG et al. [10] demonstrated that the deterioration of insulin sensitivity across an 11-year follow-up was associated with the severity of sleep breathing disorder at baseline.

In addition, several studies reported that sleep breathing disorders are associated with deterioration in insulin sensitivity. For instance, PUNJABI and BEAmER [11] found a significant correlation between insulin sensitivity measured by the frequently sampled intravenous glucose tolerance test and the severity of nocturnal desaturations after adjustments for age, sex, ethnicity and per cent of body fat. PAMIDI et al. [12] compared the insulin sensitivity (estimated from 75-g oral glucose tolerance test) of healthy young males with or without OSA matched for family and ethnic risks of developing type 2 diabetes. Males having OSA showed lower insulin sensitivity compared to males without OSA. It was recently found that insulin resistance in OSA patients was independently associated with the severity of nocturnal desaturations, but not with abdominal adiposity, in non-obese patients (unpublished data).

If insulin resistance is clearly associated with sleep breathing disorders, mechanistic explanations require further research (fig. 2). Intermittent hypoxia and sleep fragmentation associated with OSA are known to induce sympathetic activation, low-grade inflammation, activation of hypothamic-pituitary-adrenal axis
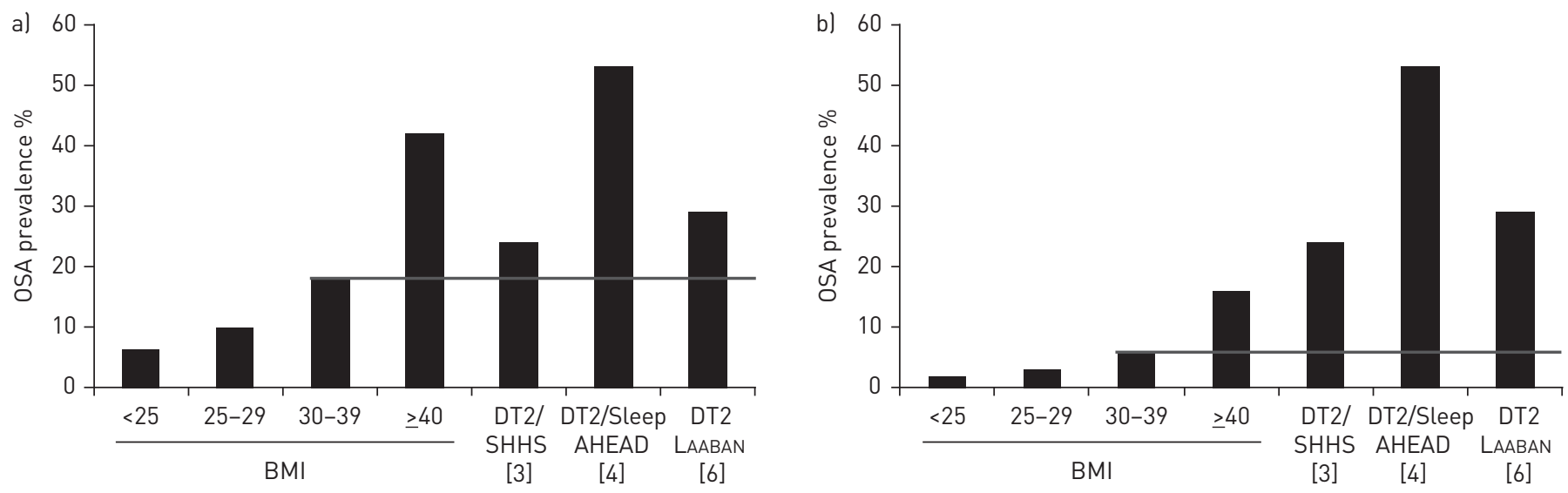

FIGURE 1 Prevalence of obstructive sleep apnoea (OSA) (apnoea/hypopnoea index $\geqslant 15$ events $\cdot \mathrm{h}^{-1}$ ) in a) males aged 50-69 years and b) females aged 50-69 years with type 2 diabetes compared with estimated prevalence $(-)$ in a general population of the same age range and body mass index (BMI). DT2: type 2 diabetes; SHHS: Sleep Heart Health Study. 


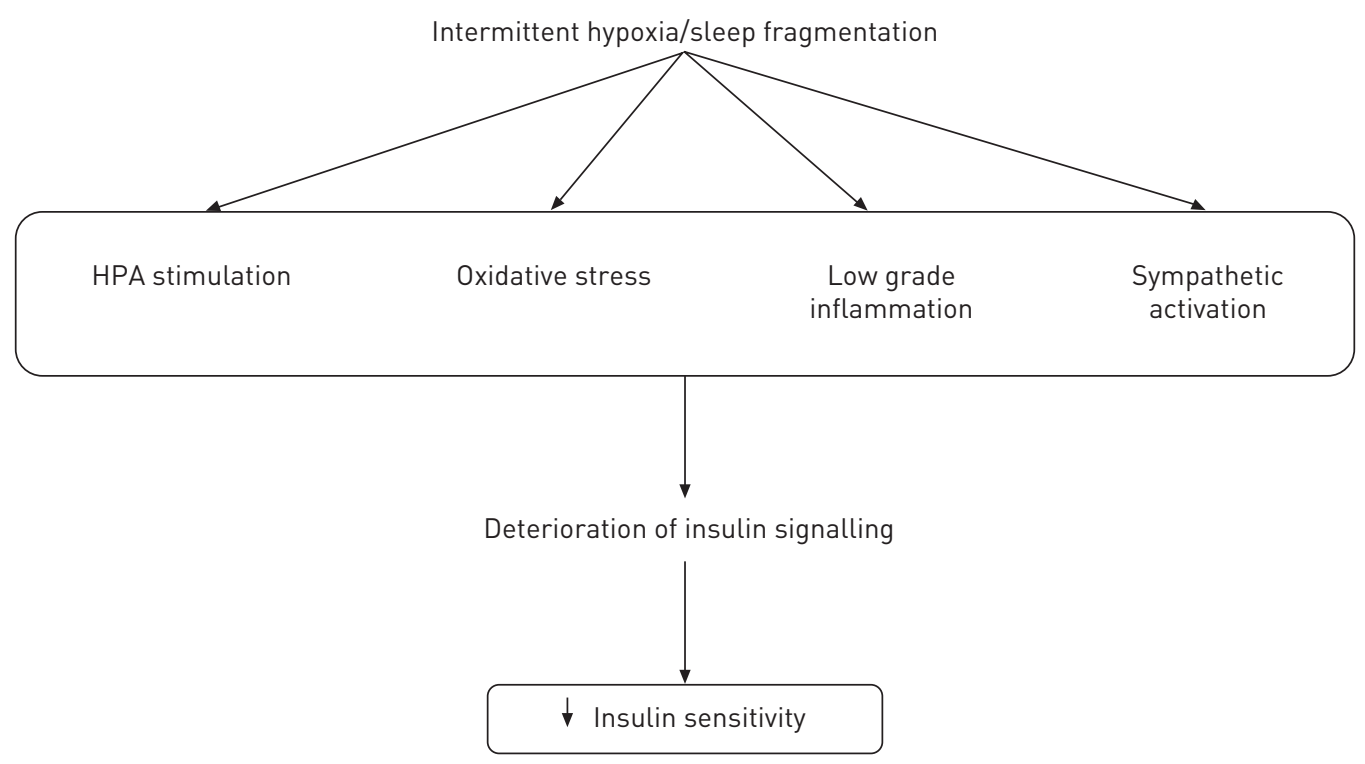

FIGURE 2 Intermediary mechanisms implicated in the deterioration of insulin sensitivity in obstructive sleep apnoea patients. HPA: hypothamic-pituitary-adrenal.

and increased oxidative stress [13]. Such intermittent hypoxia-related intermediate mechanisms are known to alter insulin signalling, as was directly demonstrated by some cultured cell and murine studies [14, 15].

Several studies, already published or ongoing, have addressed the question of the effects of continuous positive pressure (CPAP) treatment on glucose metabolism and glycaemic control in patients with type 2 diabetes. WEST et al. [16] conducted a 3-month CPAP versus sham-CPAP randomised study in patients with type 2 diabetes; this study did not show any benefit of CPAP treatment on HbAlc or insulin sensitivity. WeINSTOCK et al. [17] measured insulin sensitivity estimated from oral glucose tolerance test in patients with glucose intolerance before and after 2 months of CPAP treatment in a cross-over design with control treatment by sham-CPAP. CPAP treatment did not reverse glucose intolerance or improve insulin sensitivity, except in patients with severe OSA (AHI $>30$ events ${ }^{-h^{-1}}$ ). Finally SHARMA et al. [18] conducted a cross-over study with 3 months of CPAP compared to 3 months of sham-CPAP treatment in patients with OSA (AHI $\geqslant 15$ events $\cdot \mathrm{h}^{-1}$ ) and daily sleepiness; patients with type 2 diabetes, hypertension or dyslipidaemia were excluded. In this study, 3 months of CPAP treatment reduced HbAlc levels, as well as body weight and visceral fat accumulation. Thus, in this positive study, it is unclear whether the metabolic improvements were linked to CPAP treatment or to the reduction in fat accumulation that was associated with it. Furthermore, HoYos et al. [19] have addressed the question of the potential benefit of CPAP treatment on visceral and liver fat accumulation in a 3-month controlled study and did not find any reduction in visceral or liver fat accumulation, while CPAP treatment was associated with an increase in fatfree mass.

In conclusion, while some differing results remain, prevalence of type 2 diabetes in patients with OSA seems more frequent than in patients without OSA after controlling for confounding factors. However, OSA prevalence among patients with type 2 diabetes seems to exceed prevalence in the general population for the same age range and BMI. OSA might increase the risk of developing type 2 diabetes through deterioration in insulin sensitivity. Whether CPAP therapy is able to improve glycaemic control or insulin sensitivity or prevent incident cases of type 2 diabetes, is not clearly established yet. Results of ongoing studies as well as further studies will probably provide answer to these questions.

\section{The role of OSA in the metabolic consequences of obesity}

In recent years, the potential role of OSA in the pathogenesis of metabolic abnormalities has been extensively investigated both in patients and animal models. As summarised in a recent review [20], visceral obesity and OSA share some mechanisms, with a potential synergistic effects when the two conditions are combined.

Adipose tissue in obesity shows increased macrophage infiltration with predominance of cells with a proinflammatory pattern of activation [21]. In addition, two groups of investigators recently reported that large adipocytes were hypoxic in obese mice $[22,23]$. An increased distance between adipocytes and capillaries and insufficient capillary growth were proposed as possible mechanisms responsible for these findings [24]. 
Adipocyte hypoxia in obese animals was associated with activation of both inflammatory and hypoxia-inducible factor (HIF)-1 dependent pathways and evidence of endoplasmic reticulum stress [22, 23]. Two studies analysing subcutaneous adipose tissue from obese humans reported similar findings, i.e. lower tissue oxygen tension $\left(\mathrm{PO}_{2}\right)$ in adipose tissue of obese subjects associated with reduced circulating vascular endothelial growth factor (VEGF) levels and number of capillaries in fat $[25,26]$.

These findings raised interest on the potential role of hypoxia in the pathogenesis of metabolic abnormalities in OSA, but the effects of intermittent hypoxia in adipose tissue were unknown. ReINKE et al. [27] measured tissue $\mathrm{PO}_{2}$ in different organs during intermittent hypoxia, and reported that visceral adipose tissue showed much smaller $\mathrm{PO}_{2}$ oscillations compared to liver or muscle. Interestingly, no major differences were noted between lean and obese animals. Blunted $\mathrm{PO}_{2}$ oscillations in visceral adipose tissue during acute intermittent hypoxia or obstructive apnoeas were also reported by ALMENDROs et al. [28] in a lean rat model. In summary, experimental results do not suggest a major effect of intermittent hypoxia or obstructive apnoeas on the level of visceral adipose tissue oxygenation.

More recently, two different studies in the obesity literature have questioned that adipose tissue is hypoxic in obese humans. Goossens et al. [29] showed that abdominal subcutaneous adipose tissue $\mathrm{PO}_{2}$ is higher in obese compared to lean subjects, while HoDSON et al. [30] demonstrated that the metabolic rate of subcutaneous adipose tissue is significantly lower in obese compared to lean humans. These findings may be accounted for by decreased adipose tissue metabolism in obesity: low oxygen requirement can be expected to be associated with increased tissue $\mathrm{PO}_{2}$, low VEGF levels and decreased capillary growth [31]. The differences between results obtained in rodents and humans could be explained by the rapid rate of onset of obesity in animal models compared to the slow development of human obesity; in addition, rodent models develop a very high degree of obesity compared to humans [32]. The debate is still ongoing and additional studies in vitro and in vivo will be necessary, given the extreme complexity of the pathophysiology of human obesity. However, new experiments should be carefully designed in order to mimic physiological $\mathrm{PO}_{2}$ levels in adipose tissue. Conversely, available data were mainly obtained by exposing adipose tissue cells in vitro to extremely high or low values of $\mathrm{PO}_{2}$ [32]. Other uncertain areas relate to the potentially different effects of intermittent hypoxia on subcutaneous fat, visceral fat and brown adipose tissue (BAT). Available data have been mainly collected in subcutaneous fat in humans, and in visceral fat in rodent models. In morbidly obese patients undergoing bariatric surgery, ARON-WISNEWSKY et al. [33] found no association between intermittent hypoxia and macrophage accumulation or adipocyte size in omental or subcutaneous fat; tissue $\mathrm{PO}_{2}$ was not measured. As BAT is concerned, a trend towards decreased body weight and BAT in rats exposed to isocapnic intermittent hypoxia for 3 weeks has been reported [34]. No study to date has examined the role of chronic intermittent hypoxia on the transition from white to brown adipocytes, a topic of great interest in the current obesity literature.

\section{OSA, visceral fat and the metabolic syndrome}

The close relationship between visceral fat accumulation and OSA has been known for a long time. In 2000, VGONTZAS et al. [35] reported that the main difference between obese patients with and without OSA was the amount of abdominal visceral fat deposition, which was higher in OSA patients than in obese controls while the amount of subcutaneous fat was similar in both groups. Moreover, the amount of visceral fat, but not BMI or the amount of subcutaneous fat, showed a high degree of correlation with measures of OSA severity, such as the AHI or nocturnal intermittent hypoxemia [35].

Visceral fat accumulation is the main feature of the metabolic syndrome (MetS). Not surprisingly, MetS is highly prevalent in OSA patients, with variable rates between $50 \%$ and $>80 \%$ reported in studies worldwide (fig. 3). MetS is diagnosed in clinical practice by the NCEP-ATP (National Cholesterol Education ProgrammeAdult Treatment Panel) III criteria, which require the presence of three out of five criteria [36-45]. The number of MetS criteria is defined as the metabolic index and can be used as an indicator of severity of metabolic abnormalities. Patients with severe OSA showed a significantly higher metabolic index compared to patients with mild-to-moderate OSA [45], and this finding has been also confirmed in patients primarily identified for the presence of MetS [46] or morbid obesity [47]. An independent role of OSA on metabolic abnormalities is not strongly supported by randomised controlled trials rigorously testing the effect of CPAP on metabolism in OSA patients. A recent meta-analysis examining five controlled studies in non-diabetic OSA patients reported a significant, but quite small, effect of CPAP on metabolism [48]. These results need further confirmation by larger randomised studies.

Sex may exert a major role in the relationship between obesity and OSA. Sex differences in clinical presentation of OSA have been highlighted since the first studies on OSA, showing that OSA is less severe in females than in males with a comparable degree of obesity $[49,50]$. A recent case-control study examined adipose tissue distribution in overweight males and females with and without OSA matched for age and 


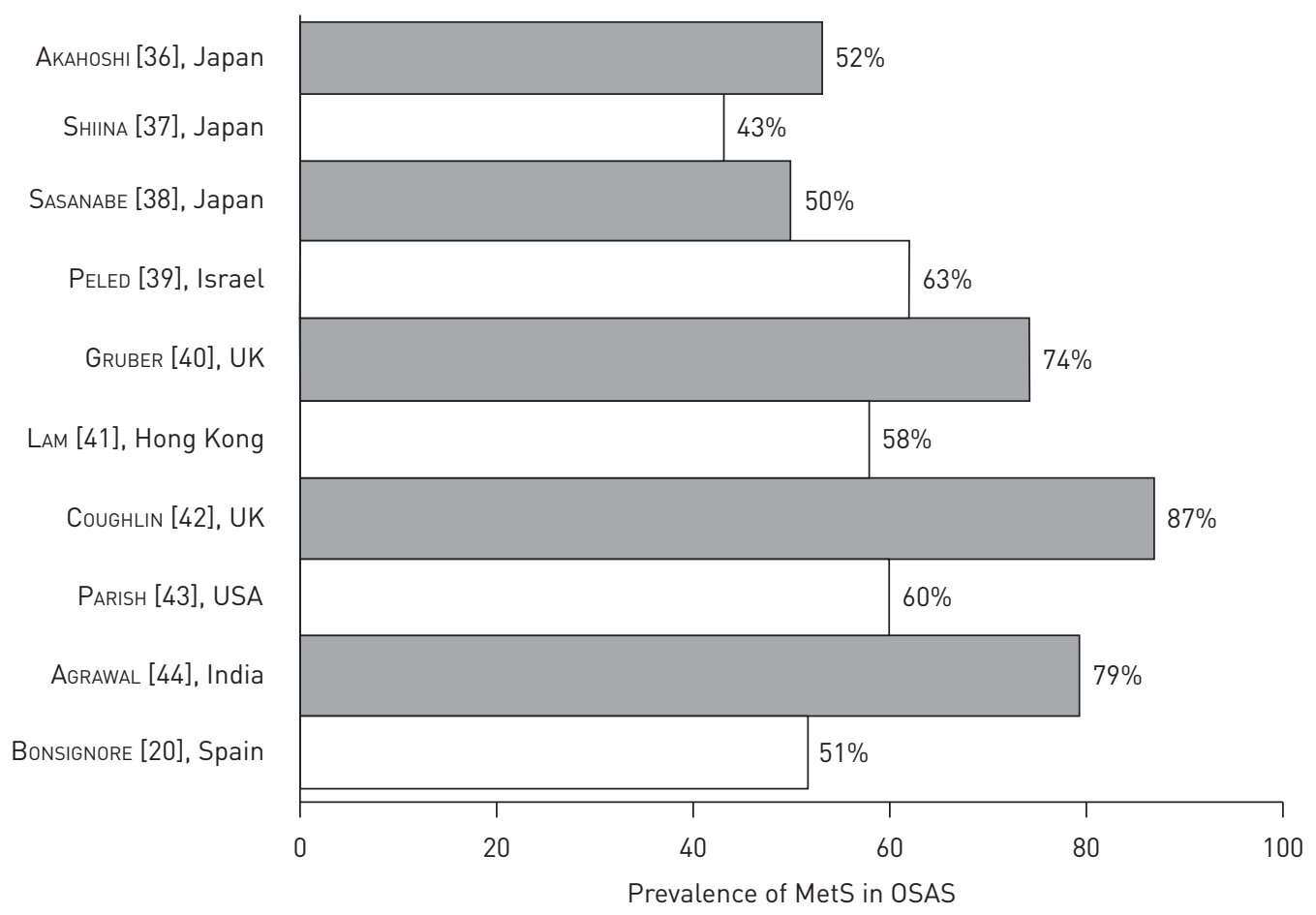

FIGURE 3 Prevalence rates of Metabolic Syndrome (MetS) in obstructive sleep apnoea syndrome (OSAS) patients worldwide.

body weight [51]. The study confirmed the known relationship between computed tomography-assessed visceral fat and OSA, and an increased visceral-to-subcutaneous fat ratio in males with OSA. However, in females visceral fat or the visceral-to-subcutaneous fat ratio did not differ between overweight females with or without OSA, suggesting that OSA in the female sex might be related to total adiposity more than to visceral adiposity [51].

Increased neck circumference is another marker of visceral adiposity frequently associated with OSA. Several studies have recently assessed its independent contribution to prediction of OSA severity, with variable results. What is missing in the current literature is the analysis of markers of obesity and metabolic abnormalities while taking sex into account. Such analysis could provide a better definition of the phenotype of OSA in obese subjects in relation to cardiovascular risk according to sex. It is possible that phenotypes with different risk profiles might occur in OSA patients, with obvious consequences regarding the need for individualised treatment. However, increased cardiovascular morbidity and mortality have been found in longitudinal studies in females with severe OSA [52], suggesting that the impact of OSA is similar in both sexes.

\section{OSA and liver damage}

The liver is an important target in patients with MetS, and liver steatosis is a major manifestation of insulin resistance [20]. Some studies have suggested that OSA may worsen liver dysfunction in obese patients by promoting the shift from simple steatosis to non-alcoholic steatohepatitis (NASH). Chronic intermittent hypoxia exposure would be the most important pathogenetic mechanism leading to NASH, as shown by studies in animal models [53]. To date, at least two studies have assessed liver morphology in humans in relation to OSA severity [33,54]; both analysed liver biopsies obtained in morbidly obese patients undergoing bariatric surgery and reported a strong association between severity of nocturnal intermittent hypoxia and liver abnormalities (steatosis and fibrosis).

Other studies have examined the association of non-alcoholic fatty liver disease and OSA with differing results, possibly explained by different features of the studied patients and methodology used to assess liver abnormalities [20]. At present, little data are available on liver morphology and function in non-morbidly obese OSA patients before and after CPAP treatment. It is possible that "usual" OSA patients may show different features compared to patients undergoing bariatric surgery. In addition, the latter patients are predominantly females and sex distribution is different from that commonly observed in clinical OSA series. 
Lifestyle interventions: metabolic benefits of exercise and weight reduction in OSA Lifestyle interventions generally encompass the key domains of diet and exercise and are driven by the vehicle of overall "behavioural change". While there is a clear benefit of weight loss amongst the generally obese population, less data is available regarding weight loss for the patient with OSA. This extends to a lack of information regarding the specific dietary and/or exercise prescription and the intensity of the weight loss recommended for patients with OSA [55].

Obesity is the most important major modifiable risk factor associated with OSA [56]. A weight gain of 10\% is associated with a $32 \%$ increase in disease severity (AHI) while a $10 \%$ weight loss resulted in a disease severity reduction of $26 \%$ [57]. OSA is an independent risk factor for the development of cardiovascular disease, hypertension and type 2 diabetes [42, 58-63]. OSA, obesity and MetS are a common disease cluster that often present to pulmonary and sleep clinicians as a mutually confounding health risk.

Visceral or central adipose tissue is thought to be the source of many of the metabolic abnormalities that contribute to the increased cardiovascular risk associated with obesity. Hence, the emphasis of lifestyle modification should be on the reduction of central fat (i.e. waist circumference) for obese individuals. There is clear evidence that $5-10 \%$ of weight loss in an obese patient translates into a marked reduction in blood pressure, lipid profile and improved insulin sensitivity, as well as improvement in other thrombotic factors and inflammatory markers for an overall reduction in the risk of coronary heart disease [64]. Although CPAP is considered the gold standard treatment for severe OSA, it variably ameliorates OSA related symptoms and hypertension, and it is unclear whether it impacts on insulin sensitivity [65-67].

Expert panels recommend lifestyle modification interventions in OSA by promoting physical activity and weight loss $[68,69]$. Weight loss is an important treatment option, especially in the non-sleepy patient who requires simultaneous OSA and metabolic risk management. Sleep-disordered breathing may impede the improvement of cardiometabolic risk profile in response to a 1-year lifestyle modification programme [70]. Following intervention, males with OSA and visceral obesity demonstrated significantly smaller reductions in BMI, waist circumference, fat mass and triglycerides and significantly smaller increases in adiponectin and high-density lipoprotein cholesterol compared to males with visceral obesity and no OSA [70]. However, more studies, including randomised trials, are required to determine whether this resistance to weight loss needs to be considered in the lifestyle prescription for the patient with OSA.

A recent systematic review and meta-analysis assessed randomised controlled trials in the area of lifestyle interventions in OSA [55]. Conservative weight loss approaches included an assortment of cognitive behavioural therapy and dietary prescription, sleep hygiene, home diets and self-managed exercise. Three randomised trials have investigated the effect of dietary weight loss versus dietary weight loss plus CPAP [71-73] and the meta-analysis observed a significant reduction in weight for those patients receiving diet plus CPAP intervention compared with the control group (table 1). The lifestyle interventions varied and did not consistently prescribe exercise or provide specific dietary recommendations or lifestyle counselling. The heterogeneity in the dietary recommendations and weight loss programmes makes it difficult to conclude that the information can be pooled and compared, and is therefore limited in generalisability.

Intensive lifestyle interventions have a variety of features including very low energy diets, supervised exercise programmes and tailored dietary prescriptions. Six randomised controlled trials have compared the effect of intensive lifestyle changes versus routine care in OSA [74-79]. The trials were mixed in duration, design and protocols employed, and no consistency was observed in the diet, exercise or structuring of the programmes employed (table 1). Overall, it is clear that intensive lifestyle interventions employing a caloric restriction and/or physical activity are effective for reducing obesity and improve the severity of OSA. Lower intensity interventions combined with CPAP therapy also work, however to a lesser degree for the same outcome measures.

Despite weight loss being important for the overall health management of patients with OSA who are overweight or obese, there are little data regarding the most effective diet for OSA patients. Very low energy diets have been widely used according to a variety of protocols; however, there are only two diets that have been tested against each other specifically in OSA patients, the Mediterranean diet versus the prudent diet [77]. The AHI during rapid eye movement sleep was reduced in the Mediterranean diet group compared to the prudent diet. Waist circumference and waist-to-hip ratio were also reduced to a greater extent in the Mediterranean diet group when compared with the prudent diet group. This supports recent evidence from a randomised trial that the Mediterranean diet supplemented with extra-virgin olive oil reduces the incidence of major cardiovascular events among persons at high cardiovascular risk [83]. Furthermore, a recent systematic review and meta-analysis revealed that the Mediterranean diet had the most pronounced effect on glycaemic control and greater weight loss in the management of type 2 diabetes [84]. There is a clear need for broader investigation comparing effectiveness of a variety of dietary protocols and macronutrient compositions in the obese OSA patient. 
Exercise is an essential component of lifestyle modification for the management of OSA, but studies specifically evaluating the efficacy of exercise training in OSA are limited by the relatively small sample sizes and the frequent lack of control groups [80, 85-88]. The methodological differences complicate any form of meaningful comparison in the exercise prescribed. The fact that obesity is so strongly linked to OSA suggests that exercise prescriptions should be designed on the basis of weight loss.

The American College of Sports Medicine (ACSM) currently recommends $>250$ minutes per week of moderate intensity cardiorespiratory exercise for clinically significant weight loss in addition to two strength training sessions [89]. The typical characteristics of the OSA patient, being sleepy and lacking energy, may compromise an individual's ability to sustainably comply with high volumes of exercise. Therefore, tailored exercise programmes fostering progressive overload and gradual conditioning of the individual may require consideration. Recent evidence suggests that exercise training may be associated with a reduction in OSA severity [78, 87, 88, 90] and, not surprisingly, improved exercise capacity [84, 85, 87, 91]. Exercise alone may also improve OSA severity without significant weight loss [77, 88, 90]. More specifically, KLINE et al. [91] tested the effects of aerobic exercise for 4 days per week in a supervised environment at moderate intensity (equating to 150 minutes per week) combined with resistance training. The exercise dose did not reach the volume recommended by the ACSM for clinically significant weight loss [89]. The exercise dose prescribed is often based on recommendations for diabetics, despite the volume not being adequate for weight loss without dietary intervention. Nevertheless, KLINE et al. [91] found significant improvement in depressive symptoms, fatigue and vigour aspects of quality of life. A significant $25 \%$ reduction in AHI $(\mathrm{p}<0.01)$ and oxygen desaturation index $(\mathrm{p}=0.03)$ was observed for the exercise group, while the decrease in body weight did not reach significance [91].

While CPAP usually ameliorates OSA symptoms of sleepiness and improves quality of life [71], it must be used in adjunct with intensive lifestyle interventions incorporating the use of very low energy diets to achieve aggressive weight reduction, followed by more sustainable eating plans and frequent exercise. A minimum of 150 minutes per week of aerobic exercise should be recommended in addition to at least two sessions of strength training to promote lean muscle gain [89]. In this way, weight re-gain can be prevented. There is a clear gap in the knowledge regarding the most effective diet to recommend to patients with OSA and furthermore, what volume of exercise will most benefit OSA and weight loss.

One of the problems impacting on delivery of the best healthcare to OSA patients is fragmentation of services and treatments. Mechanical therapies are implemented by sleep or dental specialists, while lifestyle modification is usually managed by other teams. The way forward is to integrate both clinical training and management, to ensure interdisciplinary skills in the full range of OSA therapeutics in one setting. It will be important to underpin this disruption of therapeutic silos by more randomised controlled trials built from the current knowledge base, to further unveil the role of lifestyle modification and exercise in the management of OSA $[92,93]$. While there is a clear benefit in employing intensive lifestyle interventions with or without CPAP therapy for the management of the obese OSA patient, further exploration into the most effective lifestyle prescription (encompassed by a specific diet and exercise programme) is warranted. The relative effectiveness of weight loss versus CPAP or mandibular advancement devices from a metabolic perspective is yet to be confirmed, as does a comparison of weight loss in males versus females and in comorbid type 2 diabetes. Furthermore, the feasibility and sustainability of delivering these programmes in a clinical environment must be explored. Chronic care models managing obesity, such a lifestyle modification targeting "waist loss" [64], demand further validation as does a parallel change in health promotion and the social constructs around managing obesity and OSA. It is essential for OSA and obesity chronic care to be combined, whereby there is an up skilling of both the sleep medicine and obese/metabolic medical workforce. This also necessitates the investigation of adherence issues common with CPAP use and long-term weight loss therapeutic commitment and sustainability.

\section{Conclusions}

New perspectives have opened up for the management of OSA patients due to the most recent studies on insulin resistance and diabetes in OSA and obesity, especially because such new pieces of knowledge will impact on prevention and treatment of metabolic problems. The new insight into adipose tissue biology may provide useful information to understand the real impact of OSA on adipocyte function and to design new treatment options to improve control of body weight. Finally, OSA treatment based on CPAP should be extended to include carefully targeted lifestyle interventions, since the available data confirm the positive role of diet and exercise in OSA patients, although specifically designed interventions for these patients are still lacking. Hopefully, a modern integrated approach for OSA and obesity could improve the results of OSA treatment and help decrease the high cardiovascular risk profile typical of these patients. 


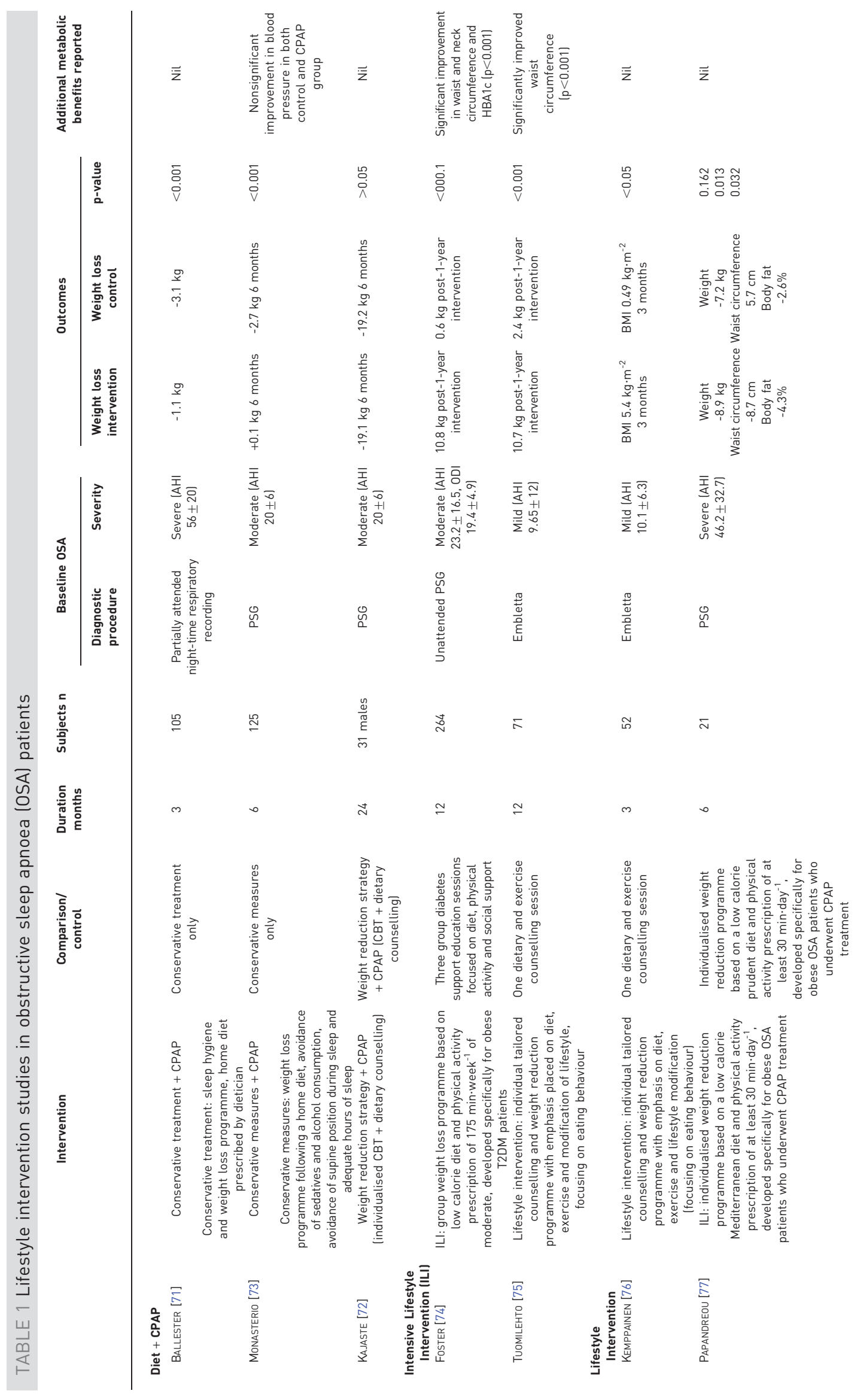




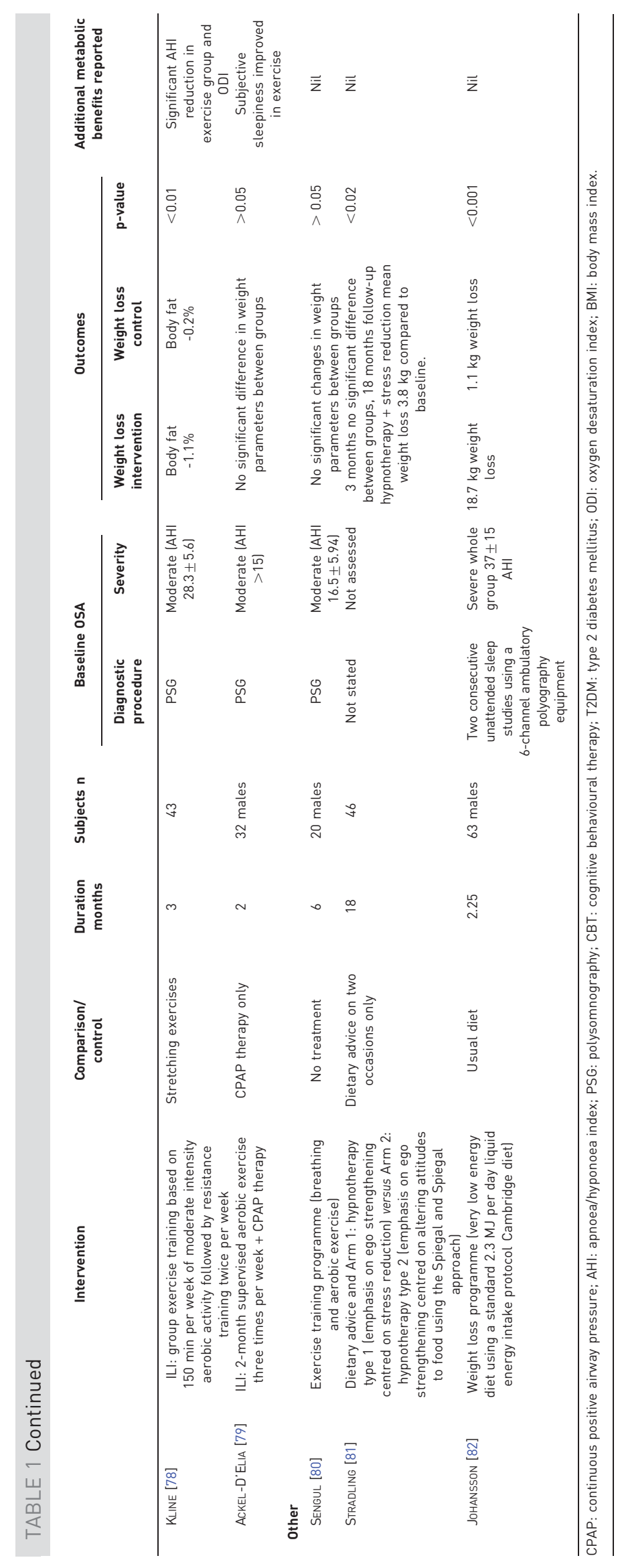




\section{References}

Pamidi S, Tasali E. Obstructive sleep apnea and type 2 diabetes: is there a link? Front Neurol 2012; 3: 126.

Reichmuth KJ, Austin D, Skatrud JB, et al. Association of sleep apnea and type II diabetes: a population-based study. Am J Respir Crit Care Med 2005; 172: 1590-1595.

3 Resnick HE, Redline S, Shahar E, et al. Diabetes and sleep disturbances: findings from the Sleep Heart Health Study. Diabetes Care 2003; 26: 702-709.

4 St-Onge MP, Zammit G, Reboussin DM, et al. Associations of sleep disturbance and duration with metabolic risk factors in obese persons with type 2 diabetes: data from the sleep AHEAD study. Nat Sci Sleep 2012; 4: 143-150. Young T, Peppard PE, Taheri S. Excess weight and sleep-disordered breathing. J Appl Physiol 2005; 99: 1592-1599.

6 Laaban JP, Daenen S, Leger D, et al. Prevalence and predictive factors of sleep apnoea syndrome in type 2 diabetic patients. Diabetes Metab 2009; 35: 372-377.

7 Foster GD, Sanders MH, Millman R, et al. Obstructive sleep apnea among obese patients with type 2 diabetes. Diabetes Care 2009; 32: 1017-1019.

8 Botros N, Concato J, Mohsenin V, et al. Obstructive sleep apnea as a risk factor for type 2 diabetes. Am J Med 2009; 122: $1122-1127$.

9 Marshall NS, Wong KK, Phillips CL, et al. Is sleep apnea an independent risk factor for prevalent and incident diabetes in the Busselton Health Study? J Clin Sleep Med 2009; 5: 15-20.

10 Lindberg E, Theorell-Haglow J, Svensson M, et al. Sleep apnea and glucose metabolism: a long-term follow-up in a community-based sample. Chest 2012; 142: 935-942.

11 Punjabi NM, Beamer BA. Alterations in glucose disposal in sleep-disordered breathing. Am J Respir Crit Care Med 2009; 179: 235-240.

12 Pamidi S, Wroblewski K, Broussard J, et al. Obstructive sleep apnea in young lean men: Impact on insulin sensitivity and secretion. Diabetes Care 2012; 35: 2384-2389.

13 Levy P, Pepin JL, Arnaud C, et al. Intermittent hypoxia and sleep-disordered breathing: current concepts and perspectives. Eur Respir J 2008; 32: 1082-1095.

14 Regazzetti C, Peraldi P, Gremeaux T, et al. Hypoxia decreases insulin signaling pathways in adipocytes. Diabetes 2009; 58: 95-103.

15 Yokoe T, Alonso LC, Romano LC, et al. Intermittent hypoxia reverses the diurnal glucose rhythm and causes pancreatic beta-cell replication in mice. J Physiol 2008; 586: 899-911.

16 West SD, Nicoll DJ, Wallace TM, et al. Effect of CPAP on insulin resistance and HbAlc in men with obstructive sleep apnoea and type 2 diabetes. Thorax 2007; 62: 969-974.

17 Weinstock TG, Wang X, Rueschman M, et al. A controlled trial of CPAP therapy on metabolic control in individuals with impaired glucose tolerance and sleep apnea. Sleep 2012; 35: 617-625B.

18 Sharma SK, Agrawal S, Damodaran D, et al. CPAP for the metabolic syndrome in patients with obstructive sleep apnea. N Engl J Med 2011; 365: 2277-2286.

19 Hoyos CM, Killick R, Yee BJ, et al. Cardiometabolic changes after continuous positive airway pressure for obstructive sleep apnoea: a randomised sham-controlled study. Thorax 2012; 67: 1081-1089.

20 Bonsignore MR, McNicholas WT, Montserrat JM, et al. Adipose tissue in obesity and obstructive sleep apnoea. Eur Respir J 2012; 39: 746-767.

21 Patel PS, Buras ED, Balasubramanyam A. The role of the immune system in obesity and insulin resistance. J Obes 2013; 2013: 616193.

22 Ye J, Gao Z, Yin J, et al. Hypoxia is a potential risk factor for chronic inflammation and adiponectin reduction in adipose tissue of ob/ob and dietary obese mice. Am J Physiol Endocrinol Metab 2007; 293: E1118-E1128.

23 Hosogai N, Fukuhara A, Oshima K, et al. Adipose tissue hypoxia in obesity and its impact on adipocytokine dysregulation. Diabetes 2007; 56: 901-911.

24 Trayhurn P. Hypoxia and adipose tissue function and dysfunction in obesity. Physiol Rev 2013; 93: 1-21.

25 Pasarica M, Sereda OR, Redman LM, et al. Reduced adipose tissue oxygenation in human obesity: evidence for rarefaction, macrophage chemotaxis, and inflammation without an angiogenic response. Diabetes 2009; 58: $718-725$.

26 Pasarica M, Rood J, Ravussin E, et al. Reduced oxygenation in human obese adipose tissue is associated with impaired insulin suppression of lipolysis. J Clin Endocrinol Metab 2010; 95: 4052-4055.

27 Reinke C, Bevans-Fonti S, Drager LF, et al. Effects of different acute hypoxic regimens on tissue oxygen profiles and metabolic outcomes. J Appl Physiol 2011; 111: 881-890.

28 Almendros I, Farré R, Planas AM, et al. Tissue oxygenation in brain, muscle, and fat in a rat model of sleep apnea: differential effect of obstructive apneas and intermittent hypoxia. Sleep 2011; 34: 1127-1133.

29 Goossens GH, Bizzarri A, Venteclef N, et al. Increased adipose tissue oxygen tension in obese compared with lean men is accompanied by insulin resistance, impaired adipose tissue capillarization, and inflammation. Circulation 2011; 124: 67-76.

30 Hodson L, Humphreys SM, Karpe F, et al. Metabolic signatures of human adipose tissue hypoxia in obesity. Diabetes 2013; 62: 1417-1425.

31 Corvera S, Czech MP. Tensions rise and blood flows over dysfunctional fat. Circulation 2011; 124: 13-16.

32 Goossens GH, Blaak EE. Adipose tissue oxygen tension: implications for chronic metabolic and inflammatory diseases. Curr Opin Clin Nutr Metab Care 2012; 15: 539-546.

33 Aron-Wisnewsky J, Minville C, Tordjman J, et al. Chronic intermittent hypoxia is a major trigger for non-alcoholic fatty liver disease in morbid obese. J Hepatol 2012; 56: 225-233.

34 Martinez D, Fiori CZ, Baronio D, et al. Brown adipose tissue: is it affected by intermittent hypoxia? Lipids Health Dis 2010; 9: 121.

35 Vgontzas AN, Papanicolaou DA, Bixler EO, et al. Sleep apnea and daytime sleepiness and fatigue: relation to visceral obesity, insulin resistance, and hypercytokinemia. J Clin Endocrinol Metab 2000; 85: 1151-1158.

36 Akahoshi T, Uematsu A, Akashiba T, et al. Obstructive sleep apnoea is associated with risk factors comprising the metabolic syndrome. Respirology 2010; 15: 1122-1126.

37 Shiina K, Tomiyama H, Takata Y, et al. Concurrent presence of metaboic syndrome in obstructive sleep apnea syndrome exacerbates the cardiovascular risk: a sleep clinic cohort study. Hypertens Res 2006; 29: 433-441. 
38 Sasanabe R, Banno K, Otake K, et al. Metabolic syndrome in Japanese patients with obstructive sleep apnea syndrome. Hypertens Res 2006; 29: 315-322.

39 Peled N, Kassirer M, Shitrit D, et al. The association of OSA with insulin resistance, inflammation and metabolic syndrome. Respir Med 2007; 101: 1696-1701.

40 Gruber A, Horwood F, Sithole J, et al. Obstructive sleep apnoea is independently associated with the metabolic syndrome but not insulin resistance state. Cardiovasc Diabetol 2006; 5: 22.

41 Lam JCM, Lam B, Lan CL, et al. Obstructive sleep apnea and the metabolic syndrome in community-based Chinese adults in Hong Kong. Respir Med 2006; 100: 980-987.

42 Coughlin SR, Mawdsley L, Mugarza JA, et al. Obstructive sleep apnoea is independently associated with an increased prevalence of metabolic syndrome. Eur Heart J 2004; 25: 735-741.

43 Parish JM, Adam T, Facchiano L. Relationship of metabolic syndrome and obstructive sleep apnea. J Clin Sleep Med 2007; 3: 467-472.

44 Agrawal S, Sharma SK, Sreenivas V, et al. Prevalence of metabolic syndrome in a north Indian hospital-based population with obstructive sleep apnoea. Indian J Med Res 2011; 134: 639-644.

45 Bonsignore MR, Barceló A, Esquinas C, et al. Metabolic syndrome, insulin resistance and excessive daytime sleepiness in non-diabetic patients with obstructive sleep apnea. Eur Respir J 2012; 39: 1136-1143.

46 Drager LF, Lopes HF, Maki-Nunes C, et al. The impact of obstructive sleep apnea on metabolic and inflammatory markers in consecutive patients with metabolic syndrome. PLoS One 2010; 5: e12065.

47 Gasa M, Salord N, Fortuna AM, et al. Impact of obstructive sleep apnea on metabolic dysfunction in severe obesity. Eur Respir J 2011; 39: 1136-1143.

48 Iftikhar IH, Khan MF, Das A, et al. Meta-analysis: continuous positive airway pressure improves insulin resistance in patients with sleep apnea without diabetes. Ann Am Thorac Soc 2013; 10: 115-120.

49 Kapsimalis F, Kryger MH. Gender and obstructive sleep apnea syndrome, part 1: clinical features. Sleep 2002; 25: 412-419.

50 Kapsimalis F, Kryger MH. Gender and obstructive sleep apnea syndrome, part 2: mechanisms. Sleep 2002; 25: 499-506.

51 Kritikou I, Basta M, Tappouni R, et al. Sleep apnoea and visceral adiposity in middle-aged male and female subjects. Eur Respir J 2013; 41: 601-609.

52 Campos-Rodriguez F, Martinez-Garcia MA, de la Cruz-Moron I, et al. Cardiovascular mortality in women with obstructive sleep apnea with or without continuous positive airway pressure treatment: a cohort study. Ann Intern Med 2012; 156: 115-122.

53 Mirrakhimov AE, Polotsky VY. Obstructive sleep apnea and non-alcoholic fatty liver disease: is the liver another target? Front Neurol 2012; 3: 149.

54 Polotsky VY, Patil SP, Savransky V, et al. Obstructive sleep apnea, insulin resistance, and steatohepatitis in severe obesity. Am J Respir Crit Care Med 2009; 179: 228-234.

55 Thomasouli MA, Brady EM, Davies MJ, et al. The impact of diet and lifestyle management strategies for obstructive sleep apnoea in adults: a systematic review and meta-analysis of randomised controlled trials. Sleep Breath 2013 [Epub ahead of print DOI: 10.1007/s11325-013-0806-7].

56 Punjabi NM, Newman AB, Young TB, et al. Sleep-disordered breathing and cardiovascular disease: an outcomebased definition of hypopneas. Am J Respir Crit Care Med 2008; 177: 1150-1155.

57 Peppard PE, Young T, Palta M, et al. Longitudinal study of moderate weight change and sleep-disordered breathing. JAMA 2000; 284: 3015-3021.

58 West SD, Nicoll DJ, Stradling JR. Prevalence of obstructive sleep apnoea in men with type 2 diabetes. Thorax 2006; 61: 945-950.

59 Peppard PE, Young T, Palta M, et al. Prospective study of the association between sleep-disordered breathing and hypertension. N Engl J Med 2000; 342: 1378-1384.

60 Shahar E, Whitney CW, Redline S, et al. Sleep-disordered breathing and cardiovascular disease: cross-sectional results of the Sleep Heart Health Study. Am J Respir Crit Care Med 2001; 163: 19-25.

61 Shamsuzzaman AS, Gersh BJ, Somers VK. Obstructive sleep apnea: implications for cardiac and vascular disease. JAMA 2003; 290: 1906-1914.

62 Wolk R, Somers VK. Obesity-related cardiovascular disease: implications of obstructive sleep apnea. Diabetes Obes Metab 2006; 8: 250-260.

63 Meslier N, Gagnadoux F, Giraud P, et al. Impaired glucose-insulin metabolism in males with obstructive sleep apnoea syndrome. Eur Respir J 2003; 22: 156-160.

64 Despres JP, Lemieux I, Prud'homme D. Treatment of obesity: need to focus on high risk abdominally obese patients. BMJ 2001; 322: 716-720.

65 Becker HF, Jerrentrup A, Ploch T, et al. Effect of nasal continuous positive airway pressure treatment on blood pressure in patients with obstructive sleep apnea. Circulation 2003; 107: 68-73.

66 Montserrat JM, Ferrer M, Hernandez L, et al. Effectiveness of CPAP treatment in daytime function in sleep apnea syndrome: a randomized controlled study with an optimized placebo. Am J Respir Crit Care Med 2001; 164: 608-613.

67 Douglas NJ, Engleman HM. Effects of CPAP on vigilance and related functions in patients with the sleep apnea/ hypopnea syndrome. Sleep 2000; 23: Suppl. 4, S147-S149.

68 Epstein LJ, Kristo D, Strollo PJ Jr, et al. Clinical guideline for the evaluation, management and long-term care of obstructive sleep apnea in adults. J Clin Sleep Med 2009; 5: 263-276.

69 Shaw JE, Punjabi NM, Wilding JP, et al. Sleep-disordered breathing and type 2 diabetes: a report from the International Diabetes Federation Taskforce on Epidemiology and Prevention. Diabetes Res Clin Pract 2008; 81: 2-12.

70 Borel AL, Leblanc X, Almeras N, et al. Sleep apnoea attenuates the effects of a lifestyle intervention programme in men with visceral obesity. Thorax 2012; 67: 735-741.

71 Ballester E, Badia JR, Hernandez L, et al. Evidence of the effectiveness of continuous positive airway pressure in the treatment of sleep apnea/hypopnea syndrome. Am J Respir Crit Care Med 1999; 159: 495-501.

72 Kajaste S, Brander PE, Telakivi T, et al. A cognitive-behavioral weight reduction program in the treatment of obstructive sleep apnea syndrome with or without initial nasal CPAP: a randomized study. Sleep Med 2004; 5: 125-131. Monasterio C, Vidal S, Duran J, et al. Effectiveness of continuous positive airway pressure in mild sleep apneahypopnea syndrome. Am J Respir Crit Care Med 2001; 164: 939-943. 

apnea among obese patients with type 2 diabetes: The Sleep AHEAD Study. Arch Intern Med 2009; 169: 1619-1626. mild obstructive sleep apnea. Am J Respir Crit Care Med 2009; 179: 320-327.

76 Kemppainen T, Ruoppi P, Seppa J, et al. Effect of weight reduction on rhinometric measurements in overweight patients with obstructive sleep apnea. Am J Rhinol 2008; 22: 410-415.

77 Papandreou C, Schiza SE, Bouloukaki I, et al. Effect of Mediterranean diet versus prudent diet combined with physical activity on OSAS: a randomised trial. Eur Respir J 2012; 39: 1398-1404.

78 Kline CE, Crowley EP, Ewing GB, et al. The effect of exercise training on obstructive sleep apnea and sleep quality: a randomized controlled trial. Sleep 2011; 34: 1631-1640.

79 Ackel-D'Elia C, Silva A, Silva R, et al. Effects of exercise training associated with continuous positive airway pressure treatment in patients with obstructive sleep apnea syndrome. Sleep Breath 2012; 16: 723-735.

80 Sengul YS, Ozalevli S, Oztura I, et al. The effect of exercise on obstructive sleep apnea: a randomized and controlled trial. Sleep Breath 2011; 15: 49-56.

81 Stradling J, Roberts D, Wilson A, et al. Controlled trial of hypnotherapy for weight loss in patients with obstructive sleep apnoea. Int J Obes Relat Metab Disord 1988; 22: 278-281.

82 Johansson K, Neovius M, Lagerros YT, et al. Effect of a very low energy diet on moderate and severe obstructive sleep apnoea in obese men: a randomised controlled trial. BMJ 2009; 339: b4609.

83 Estruch R, Ros E, Salas-Salvado J, et al. Primary prevention of cardiovascular disease with a Mediterranean diet. N Engl J Med 2013; 368: 1279-1290.

84 Ajala O, English P, Pinkney J. Systematic review and meta-analysis of different dietary approaches to the management of type 2 diabetes. Am J Clin Nutr 2013; 97: 505-516.

85 Ueno LM, Drager LF, Rodrigues AC, et al. Effects of exercise training in patients with chronic heart failure and sleep apnea. Sleep 2009; 32: 637-647.

86 Barnes M, Goldsworthy UR, Cary BA, et al. A diet and exercise program to improve clinical outcomes in patients with obstructive sleep apnea-a feasibility study. J Clin Sleep Med 2009; 5: 409-415.

87 Norman JF, Von Essen SG, Fuchs RH, et al. Exercise training effect on obstructive sleep apnea syndrome. Sleep Res Online 2000; 3: 121-129.

88 Giebelhaus V, Strohl KP, Lormes W, et al. Physical exercise as an adjunct therapy in sleep apnea - an open trial. Sleep Breath 2000; 4: 173-176.

89 Donnelly JE, Blair SN, Jakicic JM, et al. American College of Sports Medicine Position Stand. Appropriate physical activity intervention strategies for weight loss and prevention of weight regain for adults. Med Sci Sports Exerc 2009; 41: 459-471.

90 Netzer N, Lormes W, Giebelhaus V, et al. Physical training of patients with sleep apnea. Pneumologie 1997; 51: Suppl. 3, 779-782.

91 Kline CE, Crowley EP, Ewing GB, et al. Blunted heart rate recovery is improved following exercise training in overweight adults with obstructive sleep apnea. Int J Cardiol 2012 [Epub ahead of print DOI: 10.1016/ j.ijcard.2012.04.108].

92 Shneerson J, Wright J. Lifestyle modification for obstructive sleep apnoea. Cochrane Database Syst Rev 2001; CD002875.

93 Anandam A, Akinnusi M, Kufel T, et al. Effects of dietary weight loss on obstructive sleep apnea: a meta-analysis. Sleep Breath 2013; 17: 227-234. 